\title{
Studies on Aluminum-Iron Ore in-Situ Particulate Composite
}

\author{
S. Sarkar*, Akhilesh Singh \\ Department of Metallurgical and Materials Engineering, National Institute of Technology, Rourkela, India. \\ Email: "smarajit@nitrkl.ac.in
}

Received October 24 $4^{\text {th }}, 2011$; revised December $6^{\text {th }}, 2011$; accepted December $23^{\text {rd }}, 2011$.

\begin{abstract}
Discontinuously reinforced aluminium matrix composites are fast emerging as engineering materials and competing with common metals and alloys. They are gaining significant acceptance because of higher specific strength, specific modulus and good wear resistance as compared to ordinary unreinforced alloys. Reinforcing particles or short fibers normally used are silicon carbide and alumina which are added externally. Recently it has been shown that alumina particles can be produced in-situ by reaction with metallic oxides reduced by aluminium. Alumina particles thus produced are dispersed in the aluminium matrix and the elementary metal gives solid solution strengthening of the matrix. In-situ particulate composites in comparison with conventional cast particulate composites produced by external addition promote cleaner interface, eliminates interface incompatibility of the matrices with the reinforcements, help to achieve greater thermodynamic stability of reinforcement particles in the matrix at elevated temperature and also increase the possibility of developing coherency between the matrix and particles formed in-situ. The morphology and the distribution of particles strongly influence the physical and mechanical properties of composites. In the present investigation, iron ore was added to molten aluminium, aluminium-magnesium and aluminium-silicon alloys by vortex method. The iron oxides present in the iron ore are observed to react with aluminium, magnesium resulting in production ${ }^{2} \mathrm{Al}_{2} \mathrm{O}_{3}$, $\mathrm{MgO}$ and metallic iron which dissolved in liquid aluminium. The composites thus produced were cast into cast iron die. The mechanical properties of the composites were evaluated. The dry sliding wear behavior of the cast composites was studied at different loads and different sliding velocities using Pin-On-Disk configuration wear testing machine. The worn surfaces and the wear debris were also analyzed using optical microscope and scanning electron microscope.
\end{abstract}

Keywords: Wettability; Particulate Composite; Iron-Ore; In-Situ and Sliding Velocity

\section{Introduction}

Metals such as aluminium and its alloys are one of the most used material systems in the automotive and aerospace industry due to their high strength to weight ratio as well as because of their high thermal conductivity. It is mostly used in high temperature applications such as in automobile engines and in other rotating and reciprocating parts such as piston, drive shafts, brake rotors and in other structural parts which require light weight but high strength material $[1,2]$. One of the main drawbacks of this material system is that they exhibit poor tribological properties. Hence the desire in the engineering community to develop a new material with greater wear resistance and better tribological properties, without much compromising on the strength to weight ratio led to the development of metal matrix composites $[3,4]$.

A composite may be defined as a material system comprising of two or more constituent materials that remain

"Corresponding author. separate and distinct while forming a single component. The bulk material forms the continuous phase that is the matrix (e.g. metals, polymers, etc) while the other acts as the discontinuous phase that is the reinforcements (e.g. fibers, whiskers, particulates, etc). While the reinforcing material usually carries the major amount of load, the matrix enables the load transfer by holding them together $[5,6]$.

The properties of ceramic reinforced metal matrix composites have been reported much better to that of its unreinforced counterpart [7-9]. The addition of reinforcing phase significantly improves the tribological properties of aluminium and its alloy system [10]. The thinking behind the development of metal matrix composites is to combine the desirable properties of metals and ceramics. The combination of refractory particles with metallic matrix produces a material system with properties intermediate to that of matrix alloy and ceramic reinforcements. Aluminium have useful properties such as high strength, ductility, high thermal and electrical conductivity but have low stiffness whereas ceramic reinforcements are stiffer and 
stronger and have excellent high temperature resistance but they are brittle in nature $[11,12]$.

There are number of processing techniques which have been developed in recent years for processing metal matrix composites. According to the type of reinforcements, the fabrication techniques also vary considerably. The different techniques employed for metal matrix composites are powder metallurgy, spray deposition, liquid metal infiltration, squeeze casting, stir casting, etc. [13,14]. All of them have their own advantages and disadvantages.

At the early stage of development of metal matrix composites, emphasis was on preparation of fiber reinforced composites. But the high cost of reinforcement fibers, restricted the commercial exploitation of this class except for some high technology applications. The particulate reinforced metal matrix composites are gaining importance nowadays because of their low cost with advantages like isotropic properties and the possibility of secondary processing $[15,16]$.

Among the various processing techniques available for particulate or discontinuous reinforced metal matrix composites, stir casting is the technique which is in use for large quantity commercial production. This technique is most suitable due to its simplicity, flexibility and ease of production for large sized components. It is also the most economical among all the available processing techniques [17].

The present investigation has been focused on in-situ particulate [18] composite formation by utilization of low grade powdered iron ore by its dispersion into aluminum matrix by stir casting method. The objective is to form the reinforcing phase within the metallic matrix by reaction of iron ore with aluminium in the metallic melt. For increasing the wettability, silicon and magnesium were also added. The composites were characterized with the help of optical, x-ray diffraction and scanning electron microscopy. Its tensile strength, hardness and wear behavior were also evaluated.

\section{Experimental Procedure}

The aluminum-iron ore metal matrix composite was prepared by stir casting route. For this we took $500 \mathrm{gm}$ of commercially pure aluminum and desired amount of iron ore in powder form. The iron ore particles were preheated to $300^{\circ} \mathrm{C}$ for three hours to remove moisture. Commercially pure aluminum was melted in a resistance furnace. The melt temperature was raised up to $720^{\circ} \mathrm{C}$ and by purging hexachloroethane tablets degassed it. Then the melt was stirred with the help of a mild steel turbine stirrer.

The stirring was maintained between 5 to $7 \mathrm{~min}$ at an impeller speed of $200 \mathrm{rpm}$. The melt temperature was maintained $700^{\circ} \mathrm{C}$ during addition of $\mathrm{Si}$ or $\mathrm{Mg}$ and iron ore particles. The dispersion of iron ore particles were achieved by the vortex method. The melt with reinforced particulates were poured into the preheated permanent metallic mold.
The pouring temperature was maintained at $680^{\circ} \mathrm{C}$. The melt was then allowed to solidify in the mould.

Particle size of the iron ore powder was measured by Malvern particle size analyzer (Model Micro-P, range 0.05 - 550 micron). First, the liquid dispersant containing 500 $\mathrm{ml}$ of distilled water was kept in the sample holder. Then the instrument was run keeping ultrasonic displacement at 10.00 micron and pump speed $1800 \mathrm{rpm}$. The dispersant used was Sodium hexametaphosphate $(15 \mathrm{ml})$.

\subsection{Hardness}

Bulk hardness measurements were carried out on the base metal and composite samples by using standard Vickers hardness test machine. Vickers hardness measurements were carried out in order to investigate the influence of particulate weight fraction on the matrix hardness. Load applied was $10 \mathrm{~kg}$ and indenter used was square based diamond pyramid.

\subsection{Tensile Behavior}

The tensile testing of composites was done on series IX automated materials testing system 1.26 manufactured by Instron Corporation. The sample rate was $9.103 \mathrm{pts} / \mathrm{sec}$ and cross-head speed $5.0 \mathrm{~mm} / \mathrm{min}$. Standard specimens with $28 \mathrm{~mm}$ gauge length were used to evaluate ultimate tensile strength, yield strength and percent elongation.

\subsection{Sliding Wear Behavior}

Wear has been defined as the displacement of material caused by hard particles or hard protuberances where these hard particles are forced against and moving along a solid surface. Two body sliding wear tests were carried out on prepared composite specimens. A Ducom, Bangalore made computerized pin on- disc wear test machine was used for these tests. The wear testing was carried out at different sliding velocities with normal loads of $10 \mathrm{~N}, 15 \mathrm{~N}, 20 \mathrm{~N}$. A cylindrical pin of size $1.1 \mathrm{~cm}$ diameter and $2.1 \mathrm{~cm}$ length, prepared from composite casting, was loaded through a vertical specimen holder against horizontal rotating disc. Before testing, the flat surface of the specimens was abraded by using 2000 grit paper. The rotating disc was made of carbon steel of diameter $50 \mathrm{~mm}$ and hardness of $64 \mathrm{HRC}$. Wear tests were carried out at room temperature without lubrication for $30 \mathrm{~min}$. The principal objective of investigation was to study the coefficient of friction and wear. The weights were measured before and after each test segment to determine the wear loss of each sample. Scanning electron microscopy was used to analyze the morphology of the worn surfaces of sample.

\subsection{Worn Surface and Debris Analysis}

The wear debris and worn out surfaces from wear tests was analyzed with the help of optical and scanning elec- 
tron microscopy to study different wear mechanisms operating on the surface.

\section{Results and Discussion}

Iron ore analysis: Besides iron oxides, it also contains compounds of $\mathrm{Si}$ and $\mathrm{Al}$ with other elements in traces. The SEM micro-graph of the iron ore particles is shown in Figure 1.

The chemical compositions of iron ore was determined by X-ray fluorescence technique at the Rourkela steel plant. The result obtained is shown in Table $\mathbf{1}$.

Iron ore had a wide particle size distribution (Figure 2). The particle size of the ore as received condition, lies in the range from $0.1-100 \mu \mathrm{m}$.. The average particle size is about $4.78 \mu \mathrm{m}$.

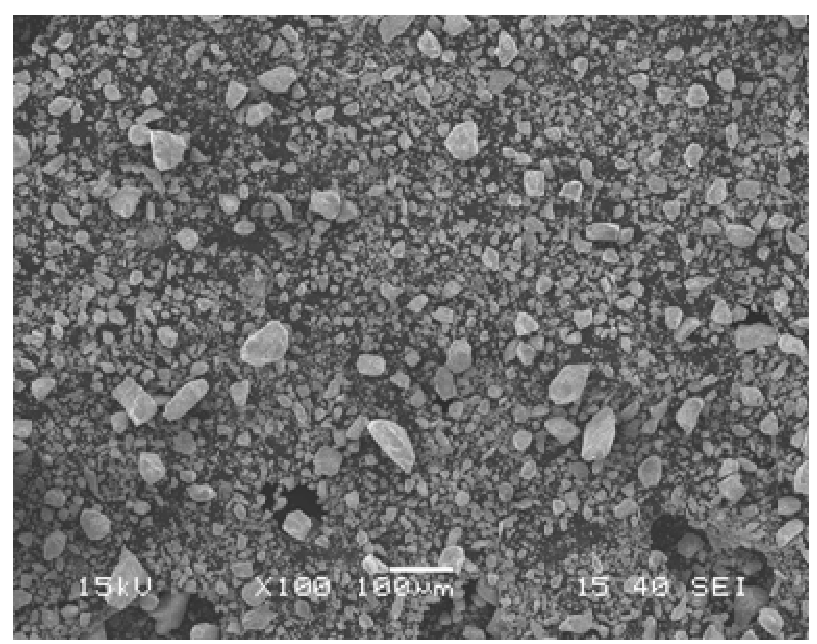

Figure 1. SEM micrograph of iron ore powder used in the present investigation.

Table 1. Composition of iron ore used.

\begin{tabular}{cc}
\hline Compounds & Percentage (\%) \\
\hline $\mathrm{Fe}$ (Total) & 57.80 \\
$\mathrm{Fe}_{2} \mathrm{O}_{3}$ & 82.65 \\
$\mathrm{Al}_{2} \mathrm{O}_{3}$ & 5.10 \\
$\mathrm{SiO}_{2}$ & 4.70 \\
\hline
\end{tabular}

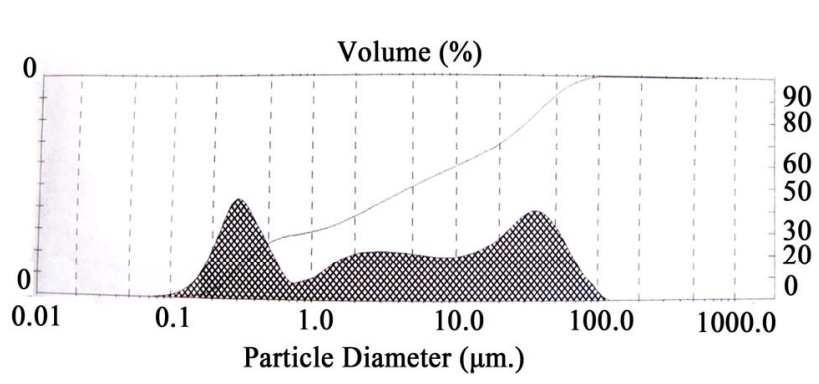

Figure 2. Particle size analysis of iron ore.

\subsection{Distribution of Particles in Particulate Composites}

The micro structure of the samples, cut from the plate casting at different locations, was observed to study the particle distribution. In the case of $\mathrm{Al}-10 \%$ iron ore, particles were not uniformly distributed throughout the casting. The particles were segregated at the top, bottom, and sides of the plates. The interior of the casting contained very few particles. This is due to the poor wettability and gravity regulated segregation of the particles. Whereas in the case of $\mathrm{Al}-2 \% \mathrm{Mg}-10 \%$ iron ore and $\mathrm{Al}-2 \% \mathrm{Si}-10 \%$ iron ore, particles were present more or less throughout the casting. The particle distribution strongly influences the physical and mechanical properties of the composites. The result shows that volume percentage of reinforcement increases with the addition of magnesium and silicon to the melt. It is probably due to better wetting conditions.

\subsection{Mechanical Properties Hardness}

The Table 2 shows that there is significant improvement in the hardness with addition of iron ore. The increase in hardness value is more in case of $\mathrm{Al}-2 \% \mathrm{Mg}$ alloys with reinforcement as compared to $2 \% \mathrm{Si}$ addition. This is may be due to the higher volume percentage of the reinforcement. In the case of alloys added with $\mathrm{Mg}$ there is a possibility of $\mathrm{MgO}$ and $\mathrm{MgAl}_{2} \mathrm{O}_{4}$ formation and possibly these are much finer and give greater strengthening in the composite.

\subsection{Tensile Properties of Composites}

From the Table 3, it is clear that addition of iron ore leads to improvement in the ultimate tensile strength of the aluminium alloy. The addition of Magnesium improves the strength of the composites significantly.

Table 2. Vickers hardness test.

\begin{tabular}{lc}
\hline Sample & Average Hardness (Hv) \\
\hline As cast Al & 44 \\
Al-5\% iron ore & 53 \\
Al-2\% Mg-5\% iron ore & 71 \\
Al-10\% iron ore & 56 \\
Al-2\% Si-10\% iron ore & 84 \\
Al-2\% Mg-10\% iron ore & 93 \\
\hline
\end{tabular}

Table 3. Tensile properties of composites.

\begin{tabular}{lccc}
\hline Sample & $\begin{array}{c}\text { Yield strength } \\
(\mathrm{MPa})\end{array}$ & $\begin{array}{c}\text { U.T.S. } \\
(\mathrm{MPa})\end{array}$ & $\begin{array}{c}\text { Percent } \\
\text { elongation }\end{array}$ \\
\hline 6063 Al alloy (theoretical) & - & 131.00 & 18.00 \\
Al-10\% iron ore & 82.48 & 243.70 & 6.107 \\
Al-2\% Si-10\% iron ore & 140.70 & 249.10 & 3.968 \\
Al-2\% Mg-10\% iron ore & 277.41 & 383.20 & 2.589 \\
\hline
\end{tabular}


The composites prepared in the present study are reinforced with particles of variety of simple and complex oxides as seen from the XRD analysis given above (Figure 3). The size range of the particles is also very wide as compared to the composites investigated earlier. The size varies from the very fine ones of $0.1 \mu \mathrm{m}$ to the coarse one of $100 \mu \mathrm{m}$. The size range of the iron ore particles present indicates that the composite prepared can be considered as dispersion strengthened as well as particle reinforced composite. Thus the strengthening of composite can be due to dispersion strengthening as well as due to particle reinforcement. Dispersion strengthening is due to the incorporation of very fine particles, which help to restrict the movement of dislocations, whereas in particle strengthening, load sharing is the mechanism. The improvement in strength may also result from the dissolution of iron released on aluminothermic reduction of iron oxides present in iron ore. Though, it is very difficult to quantify the contribution of these factors in improvement of strength.

\subsection{Dry Sliding Wear Behavior}

Wear behavior of different composites were studied with different parameter like sliding velocity and applied loads. There result and discussion are given in the following subsections.

\subsection{Effect of Sliding Distance}

Figure shows the relationship between weight loss and sliding distance.

Figures 4 and 5 shows wear curves of MMCs speci- men with $10 \%$ iron ore, $10 \%$ iron ore with $2 \% \mathrm{Si}$ and $10 \%$ iron ore with $2 \% \mathrm{Mg}$ content with normal load of $10 \mathrm{~N}$ and $20 \mathrm{~N}$. All the MMCs showed a very small initial nonlinear wear regime. After a certain sliding distance, the wear has increased linearly with time indicating steady state wear regime. The transition from initial wear regime to steady state regime has taken place within few minutes (2 - 3 min) of commencement of the test. From the graph (Figure 4) it is evident that the wear resistance of composite is much greater than the commercially pure aluminium. Bulk wear decrease with addition of magnesium.

Incorporation of iron ore content significantly reduces wear. This evidence from the amount of wear observed for commercially pure aluminum and composite with $2 \% \mathrm{Mg}$ $10 \%$ iron ore content. This is because of the presence of hard iron ore particle which will increase the overall bulk hardness.

In the initial wear regime, the reinforced particles act as load carrying elements and as inhibitors against plastic deformation and adhesion of matrix material. In the later stages of wear regime, the worn particles get dislodged from their positions in the matrix and get mixed with the wear debris. The wear debris containing matrix material, worn particles and iron from the disc get pushed into the craters formed by dislodging of particles and act as load bearing elements.

\subsection{Effect of Variation in Sliding Velocity}

Variation in sliding velocity was achieved by varying rotational speed of the disc with different rpm keeping track diameter constant. The wear of the composites are significantly increased with increase in sliding velocity (Figure 6).

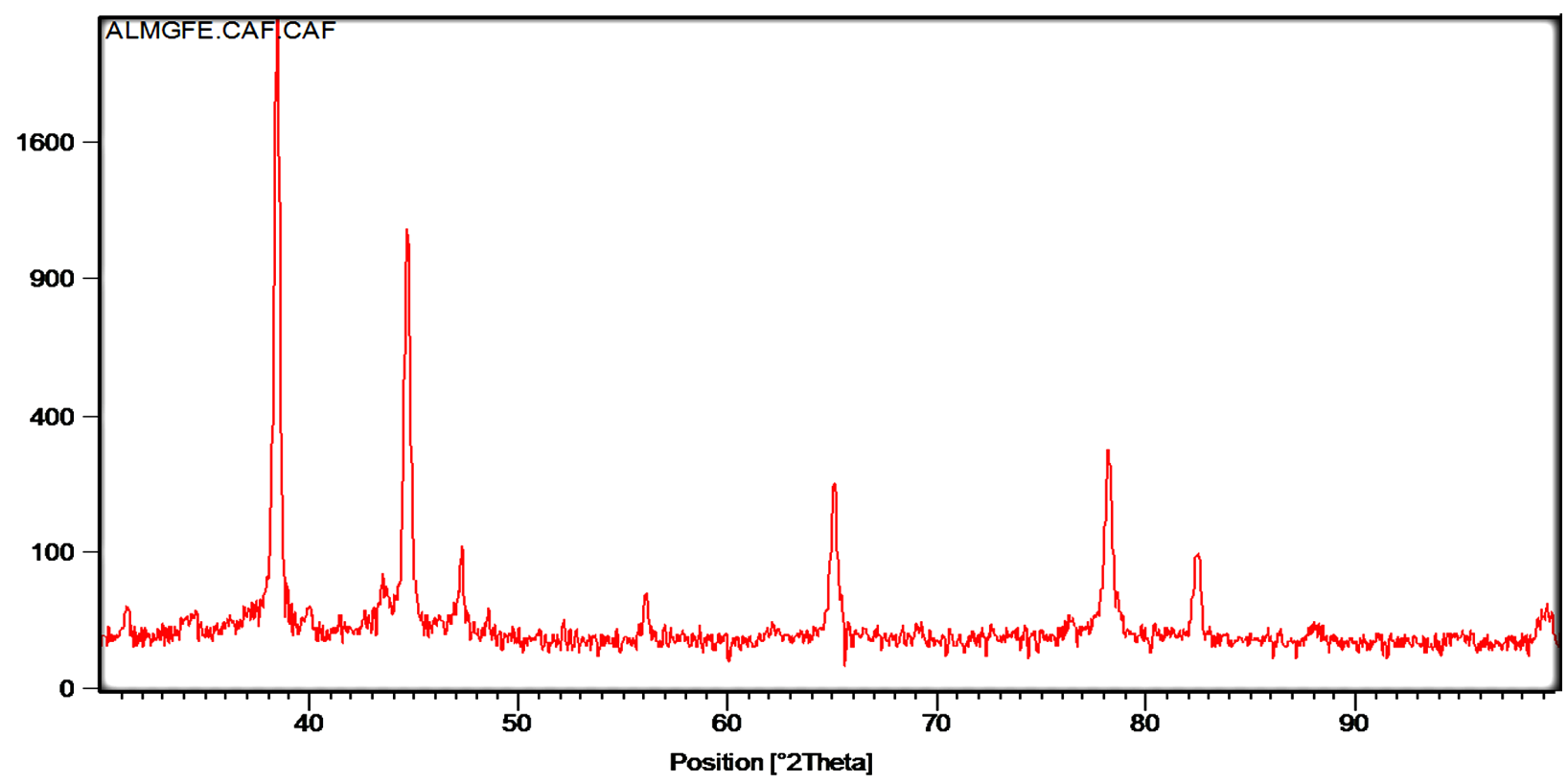

Figure 3. XRD pattern for Al-2\% Mg-10\% Iron ore composite. 

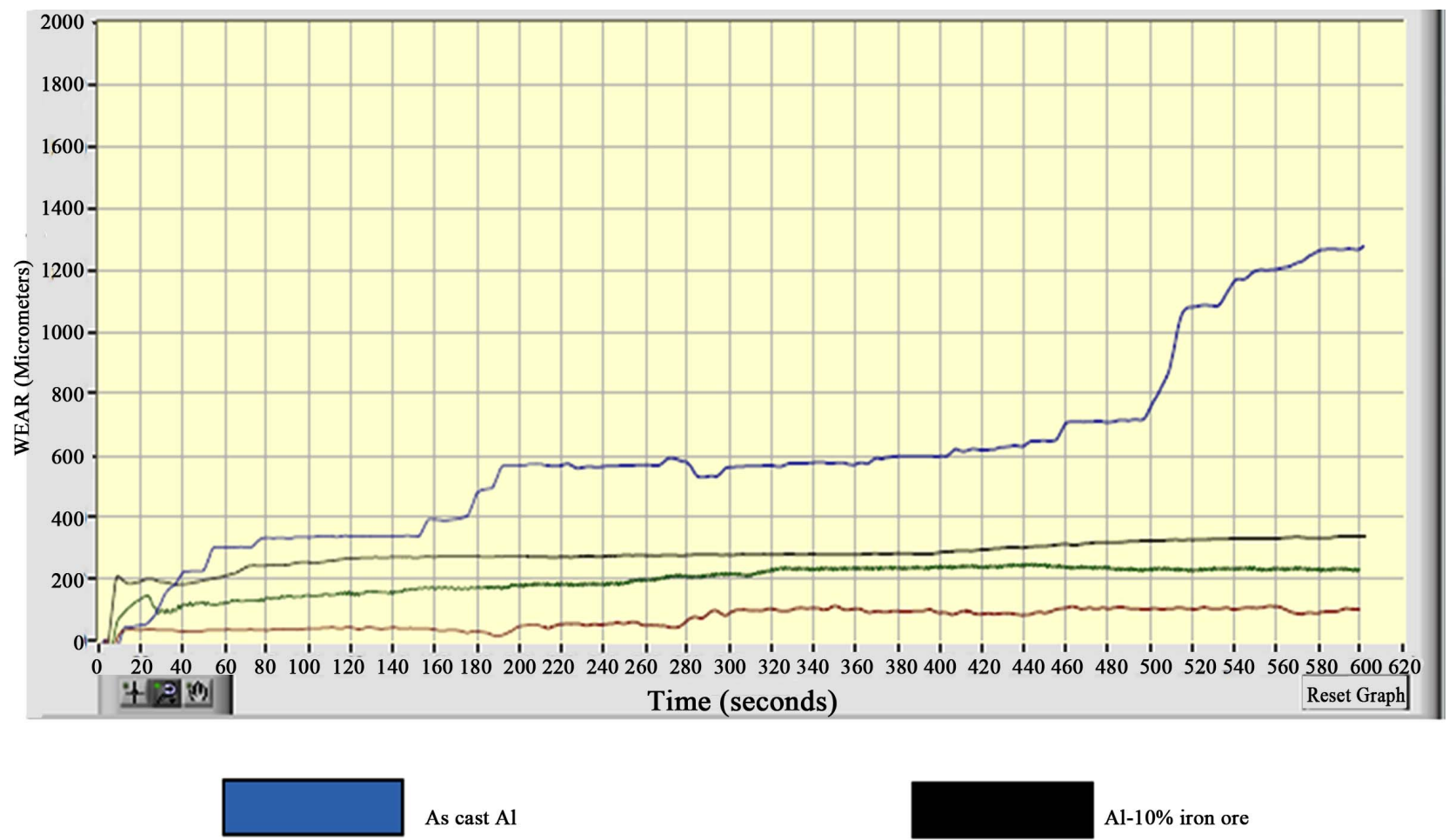

Al-10\% iron ore

Al-2\%Si-10\% iron ore

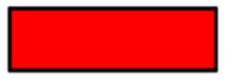

$\mathrm{Al}-2 \% \mathrm{Mg}-10 \%$ iron ore

Figure 4. Wear behavior with different composition under normal load of $10 \mathrm{~N}$.

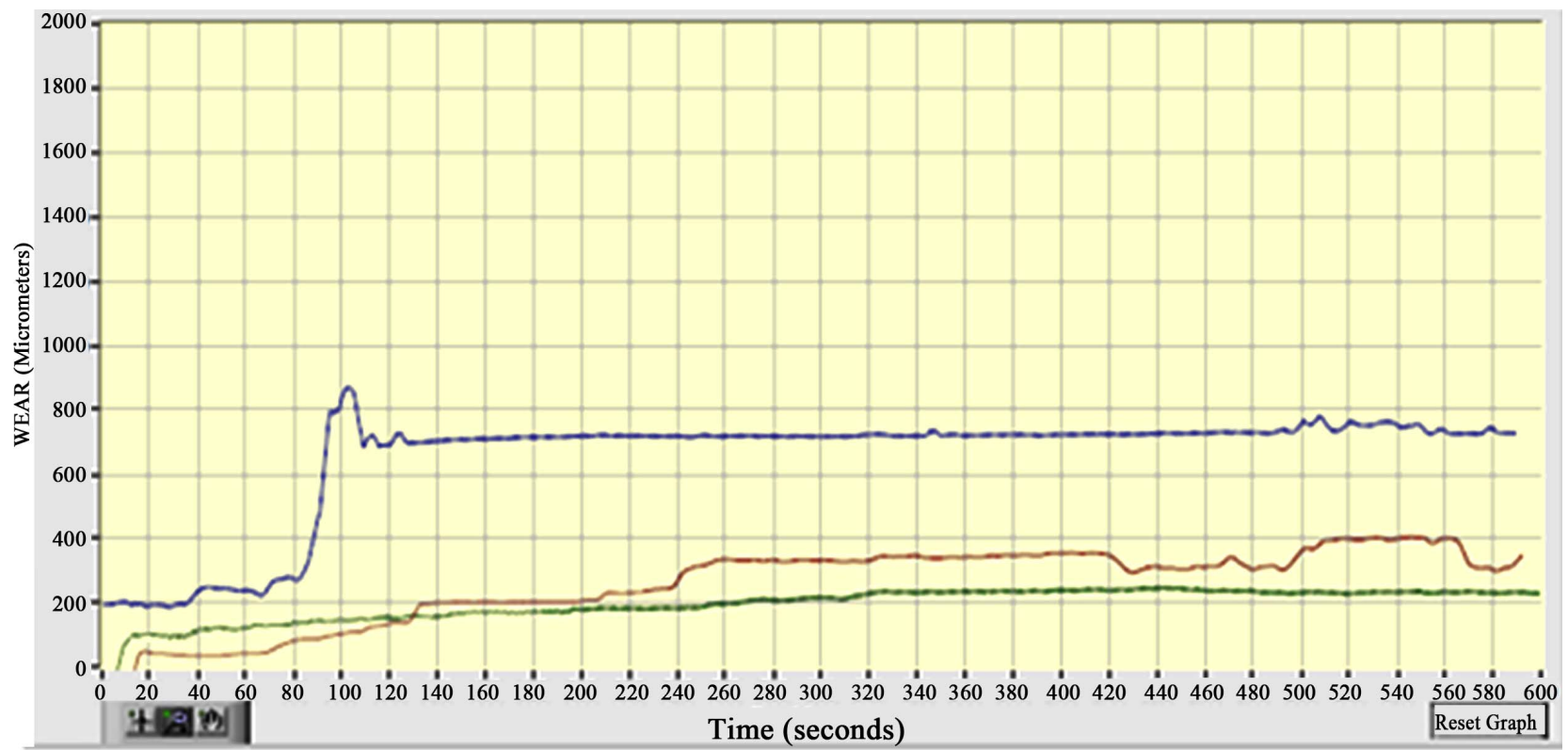

Al-10\% iron ore

$\mathrm{Al}-2 \% \mathrm{Si}-10 \%$ iron ore

$\mathrm{Al}-2 \% \mathrm{Mg}-10 \%$ iron ore

Figure 5. Wear behavior with different composition under normal load of $20 \mathrm{~N}$. 


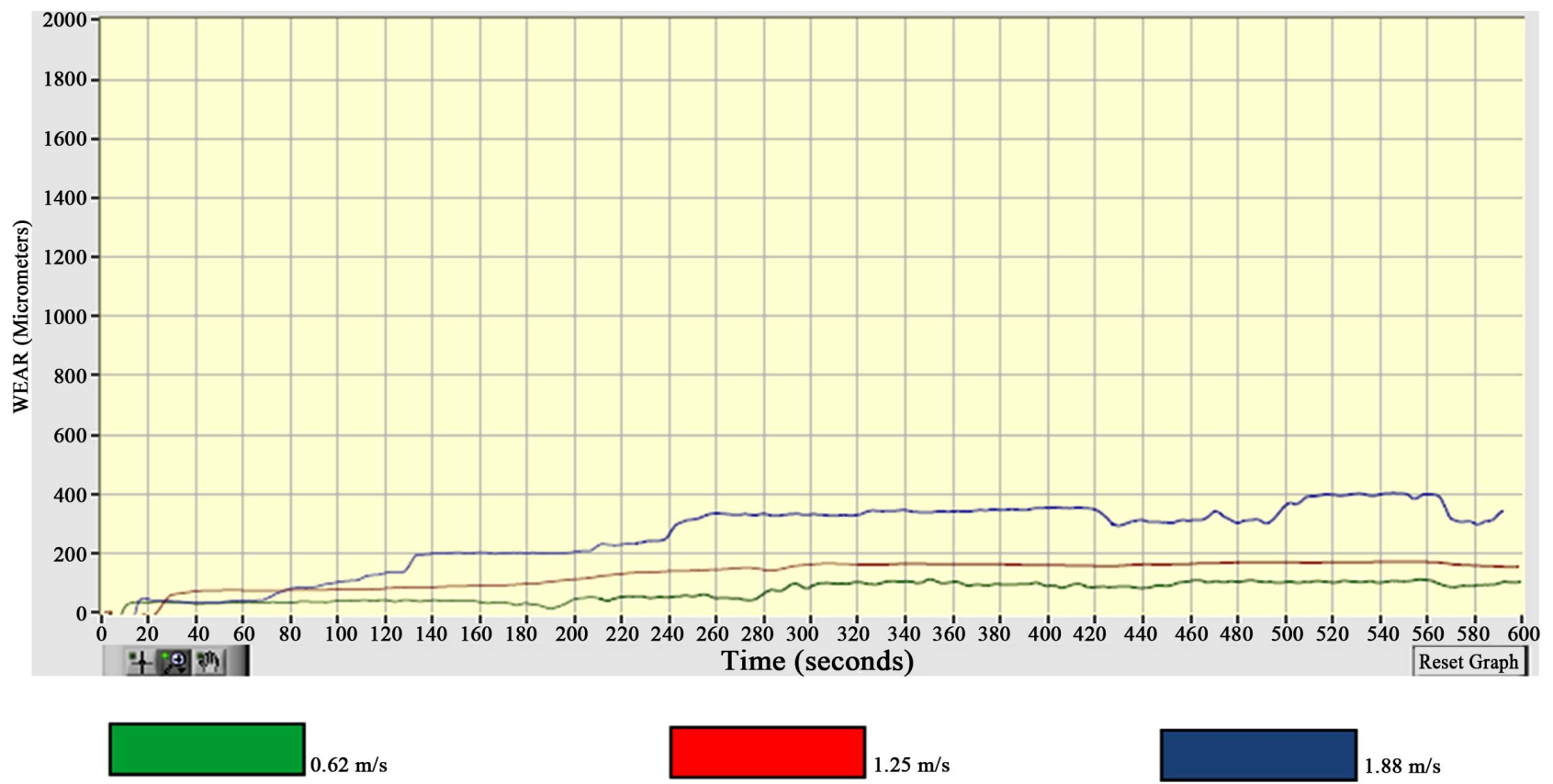

Figure 6. Wear behavior with variation in sliding velocity at constant load (20N).

\subsection{Effect of Variation in Normal Load}

Figure 7 shows the relation between applied load and wear of the MMC (Al-2\% Mg-10\% Iron ore) for a particular velocity of $1.25 \mathrm{~m} / \mathrm{sec}$. The amount of wear has been increased with increase in normal load. Like other Al composites, Al-iron ore composites also have an increasing trend of wear with applied load due to deformation and generation of cracks within oxide films that might acts as a three body wear on removal of the particles, thereby increase the wear rate at higher loads.

\subsection{Frictional Characteristics}

The coefficient of friction has decreased with increased iron ore as evident from Figure 8. In the test, normal load of $10 \mathrm{~N}$ and sliding velocity of $1.25 \mathrm{~m} / \mathrm{sec}$ were used. Al$2 \% \mathrm{Mg}-10 \%$ iron ore showed lowest coefficient of friction (as low as 0.02), whereas Al-10\% Iron ore showed the highest coefficient of friction(as high as 0.175 ). The presence of reinforcing particles will reduce the friction by providing point contact between counter face and pin. The volume of the reinforcing particle is highest in case of $\mathrm{Al}-2 \% \mathrm{Mg}-10 \%$ iron ore composite and lowest in the case of Al-10\% iron ore.

\subsection{Wear Mode and Mechanism}

There is a continuous removal of material from the surface, whenever there is a sliding motion between two surfaces in contact. The extent may vary depending on various factors like type of material in contact, the applied load, sliding velocity, temperature, moisture, etc. In the present work, both the surfaces are different and the material undergoes deformation upto sub-surface level starting from asperities present.

The study of the worn surfaces of aluminum-iron ore composites under optical (Figure 9) and scanning electron microscopy shows that at lower load, the worn surface has relatively less ploughing and cutting, as shown in Figure 10(a). However, at higher loads and higher sliding velocities, fractured particles are frequently present on the worn surface (Figures 10(c) and (d))

The study of wear tracks at different applied loads and different sliding velocities shows broken oxide films on wear tracks, deep grooves and delamination of surface. The wear rate was observed to decrease continuously with increase in hardness of the composite. Wear properties of Al-Mg-Iron ore composites are found to be superior than that of as cast Aluminium and Al-Iron ore composites

The results clearly indicates the accumulation of strain in the sliding surface and subsurface level which causes plastic deformation and nucleation and growth of microcracks which finally becomes the source of wear failure and hence loss of material at the interface. Optical and scanning electron microscopic examination of the worn pin surfaces identified different wear mechanism operating under various sliding conditions such as abrasion, oxidation and delamination.

The characteristics of the wear debris generated during the wear tests have been studied in detail. The scanning electron micrograph of the wear debris in Figure 10 shows fine particles at low load and large flaky particles at higher loads. The debris varies markedly in color, size, shape and composition. The material during wear testing, due to slid- 
ing motion eventually produces wear debris. If the stress produced in the material during sliding motion is more than the fracture stress of the particles, they lose their ability to support the load. The direct contact of the aluminium matrix with the counter face imposes large plastic strains on the pin surface. This gives rise to crack formation. Delamination of the wear surfaces also contributes to debris formation.
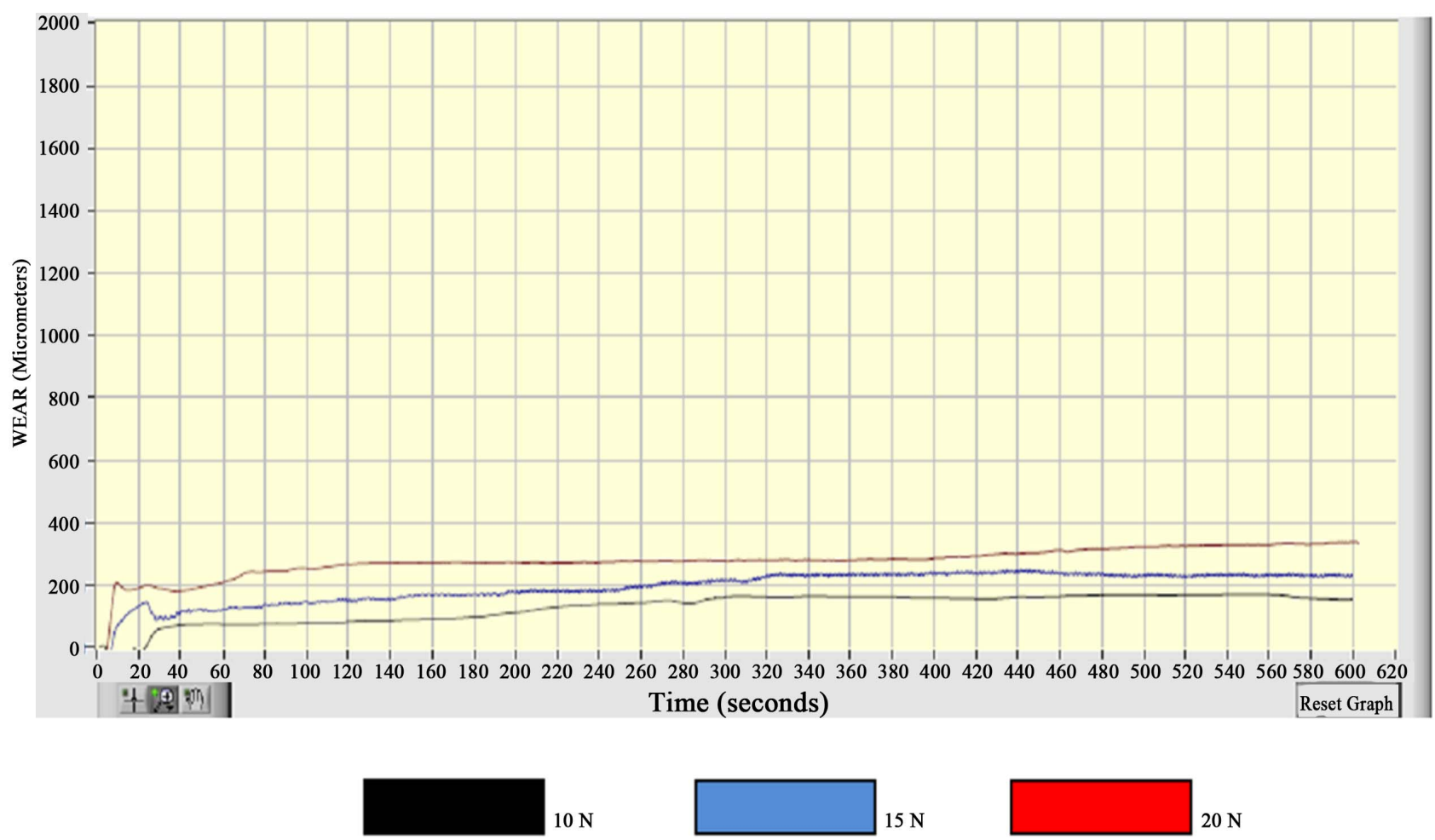

Figure 7. Wear behavior with variation in normal load at constant velocity.

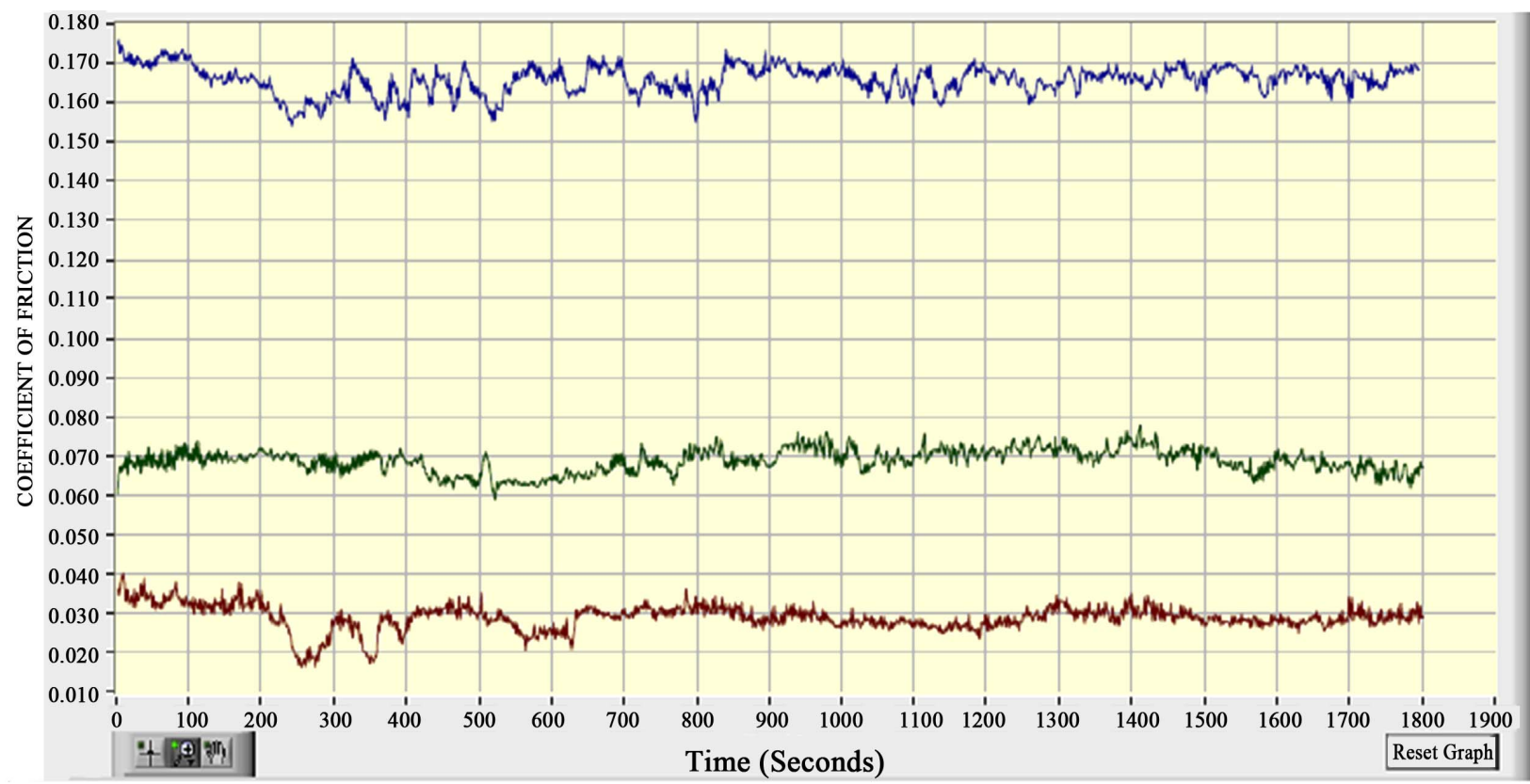

Al- $10 \%$ iron ore

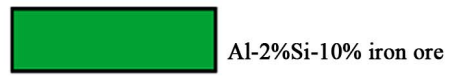

$\mathrm{Al}-2 \% \mathrm{Mg}-10 \%$ iron ore

Figure 8. Variation of coefficient of friction with composition of the composite. 


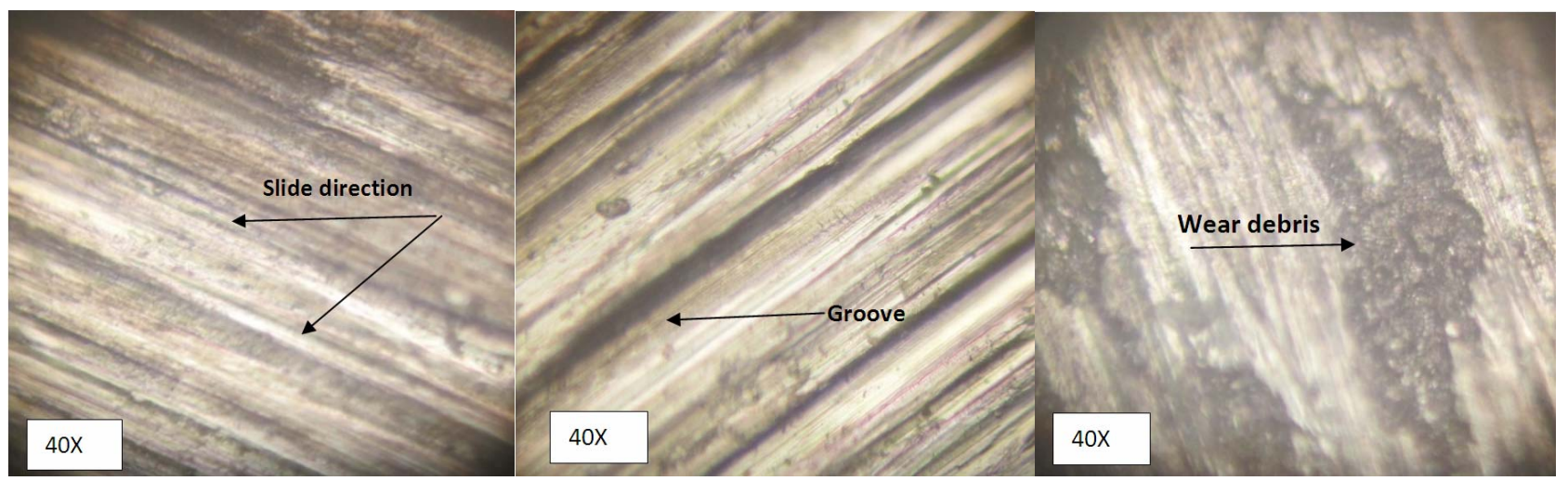

(a)

(b)

(c)

Figure 9. Optical micrograph of worn surface of Al-2\%Mg-10\% iron ore. (a) Micrograph with grooves and scratch marks; (b) Deep and large grooves at higher loads; (c) Wear debris filling the valleys in the wear surface.

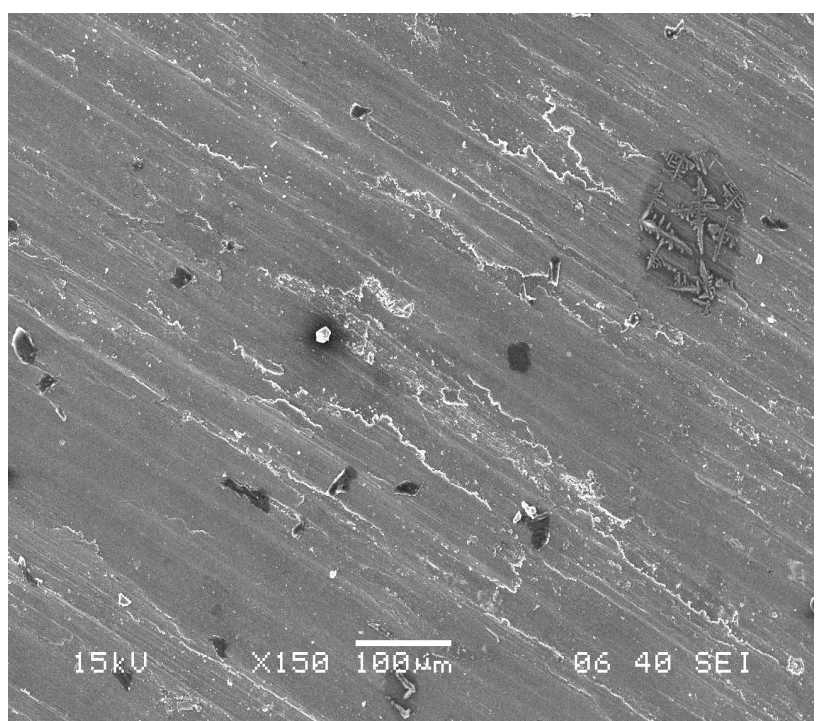

(a)

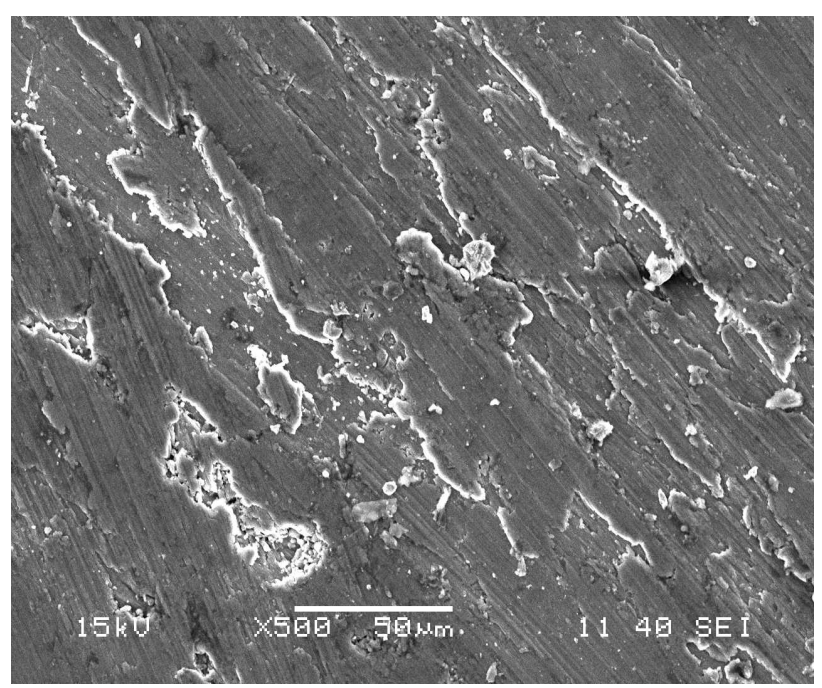

(c)

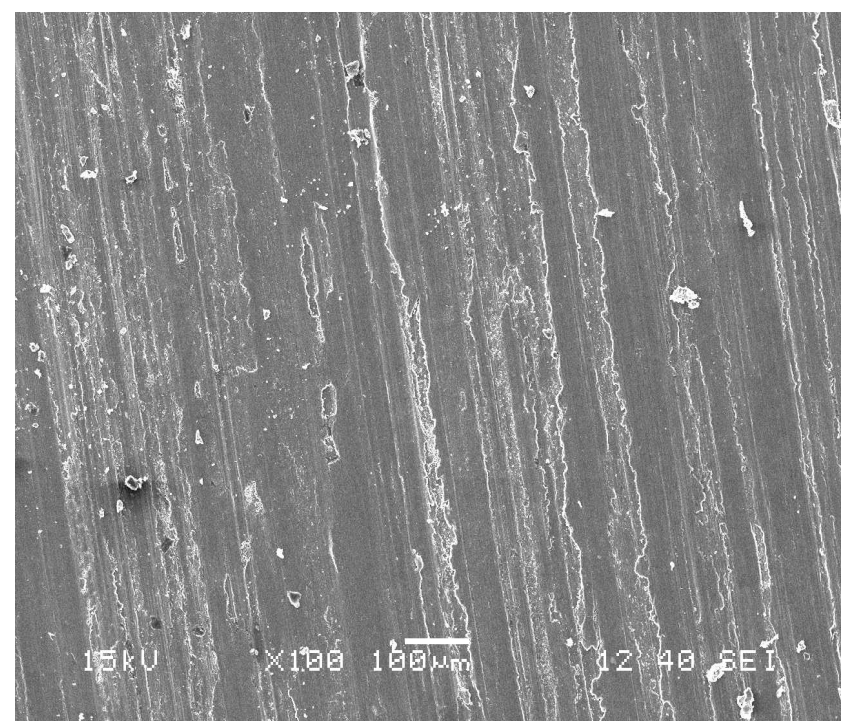

(b)

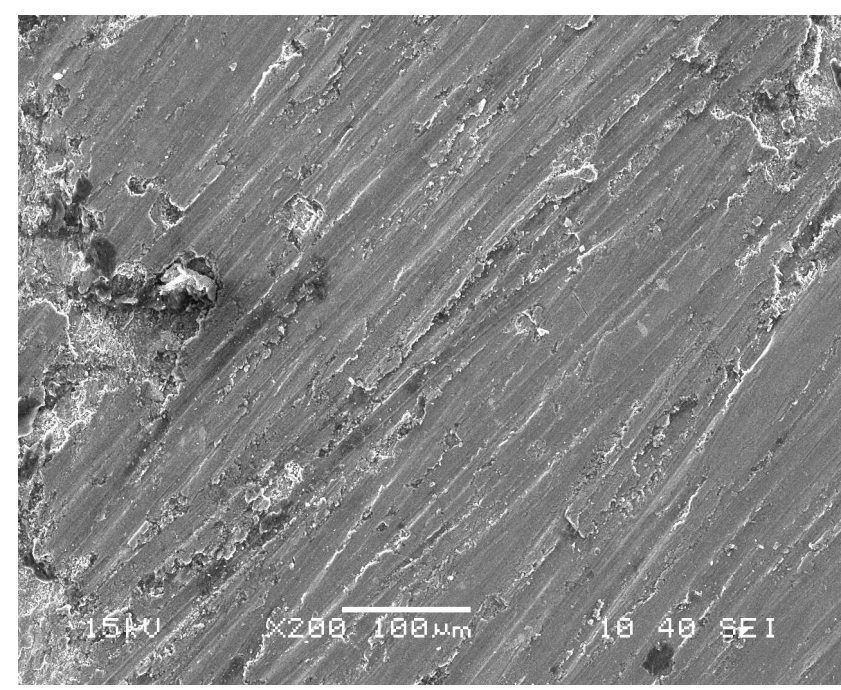

(d)

Figure 10. SEM micrograph of worn surface of composites. (a) Al-iron ore200 rpm $10 \mathrm{~N}$; (b) Al-iron ore300 rpm $10 \mathrm{~N}$; (c) Al-Mg-iron ore at $300 \mathrm{rpm} 20 \mathrm{~N}$; (d) Al-Mg-iron ore at $400 \mathrm{rpm} 20 \mathrm{~N}$. 


\section{Conclusions}

The following conclusions may be drawn from the project work:

1) Iron ore upto $10 \%$ by weight can be successfully added to aluminium by vortex method to produce composites that can be die cast.

2) There is appreciable reaction between the iron ore and the melt producing finer particles of complex oxides.

3) The oxide particles and the unreacted particles of iron ore give sufficient improvement in strength and hardness of the composite.

4) Addition of $\mathrm{Mg}$ and $\mathrm{Si}$ improves the wettability of iron ore with aluminium melt and thus increase the amount of reinforcing phase in the composite.

5) The wear resistance has improved significantly by addition of iron ore.

6) The metal matrix composites shows better wear resistance due to its superior load bearing capacity.

7) Increase in normal load and sliding velocity increases the magnitude of wear and frictional force.

8) Different wear mechanisms were observed at different normal loads, compositions and sliding velocities.

\section{Acknowledgements}

The authors would like to thank the National Institute of Technology (NIT), Rourkela for providing the necessary financial and infrastructural supports.

\section{REFERENCES}

[1] I. A. Ibrahim, F.A. Mohamed, E.J. Lavernia, "Metal Matrix Composites-A Review," Journal of Material Science, Vol. 26, No. 5, 1991, pp. 1137-1157. doi:10.1007/BF00544448

[2] S. Basavarajappa, G. Chandramohan, A. Mahadevan, M. Thangavelu, R. Subramanian and P. Gopalakrishnan, "Influence of Sliding Speed on the Dry Sliding Wear Behaviour and the Subsurface Deformation on Hybrid Metal Matrix Composite," Wear, Vol. 262, No. 7-8, 2007, pp. 1007-1012. doi:10.1016/j.wear.2006.10.016

[3] I. Sinclair and P. J. Gregson, "Structural Performance of Discontinuous Metal Matrix Composites," Material Science Technology, Vol. 13, No. 9, 1997, pp. 709-725.

[4] A. P. Sannino and H. J. Rack, "Dry Sliding Wear of Discontinuously Reinforced Aluminium Composites: Review and Discussion," Wear, Vol. 189, No. 1-2, 1995, pp. 119. doi:10.1016/0043-1648(95)06657-8

[5] B. C. Pai, T. P. D. Rajan and R. M. Pillai, "Aluminium Matrix Composite Castings for Automotive Applications," Indian Foundry Journal, Vol. 50, 2004, pp. 30-39.

[6] M. K. Surappa, "Aluminium Matrix Composites: Chal- lenges and Opportunities," Sadhana, Vol. 28, No. 1-2, 2003, pp. 319-334. doi:10.1007/BF02717141

[7] K. G. Satyanarayana, R. M. Pillai and B. C. Pai, "Recent Developments and Prospects in Cast Aluminium Matrix Composites," Transactions of the Indian Institute of Metals, Vol. 55, No. 3, 2002, pp. 115-130.

[8] F. Gul and M. Acilar, "Effect of the Reinforcement Volume Fraction on the Dry Sliding Wear Behaviour of Al-10Si/SiCp Composites Produced by Vacuum Infiltration Technique," Composites Science and Technology, Vol. 164, No. 13-14, 2004, pp. 1959-1970.

[9] S. F. Corbin and D. S. Wilkinson, "The Influence of Particle Distribution on the Mechanical Response of a Particulate Metal Matrix Composite," Acta Metallurgica et Materialia, Vol. 42, No. 4, 1994, pp. 1311-1318. doi:10.1016/0956-7151(94)90147-3

[10] S. Sarkar, S. Tripathy and S. Mohan, "Effect of Si and Mg Addition on Dry Sliding Wear of Al-Fly Ash Metal Matrix Composite," Journal of Composite Materials, Vol. 9, No. 49, 2009, pp. 1-17.

[11] S. B. Prabu, L. Karunamoorthy, S. Kathiresan and B. Mohan, "Influence of Stirring Speed and Stirring Time on Distribution of Particles in Cast Metal Matrix Composite," Journal of Materials Processing Technology, Vol. 171, No. 20, 2006, pp. 268-273. doi:10.1016/j.jmatprotec.2005.06.071

[12] N. chawla and Y.-L. Shen, "Mechanical Behavior of Particle Reinforced Metal Matrix Composites," Advanced Engineering Materials, Vol. 3, No. 6, 2001, pp. 357-370. doi:10.1002/1527-2648(200106)3:6<357::AID-ADEM35 7>3.0.CO;2-I

[13] S. M. L. Nai and M. Gupta, "Influence of Stirring Speed on the Synthesis of $\mathrm{Al} / \mathrm{Sic}$ Based Functionally Gradient Materials," Composite Structures, Vol. 57, No. 1-4, 2002, pp. 227-233. doi:10.1016/S0263-8223(02)00089-2

[14] J. Hashim, L. Looney and M. S. J. Hashmi, "Metal Matrix Composites: Production by the Stir Casting Method," Journal of Materials Processing Technology, Vol. 92-93, 1999, pp. 1-7. doi:10.1016/S0924-0136(99)00118-1

[15] P. K. Ghosh and S. Ray, "Fabrication and Properties of Compocast Aluminium-Alumina Particulate Composites," Indian Journal of Technology, Vol. 26, 1988, pp. 83-94.

[16] D. J. Lloyd, "Particle Reinforced Aluminium and Magnesium Matrix Composites," International Materials Reviews, Vol. 39, No. 1, 1994, pp. 1-23

[17] N. Aniban, R. M. Pillai and B. C. Pai, "An Analysis of Impeller Parameters for Aluminium Metal Matrix Composites Synthesis," Materials and Design, Vol. 23, No. 6, 2002, pp. 553-556. doi:10.1016/S0261-3069(02)00024-9

[18] R. M. Aikin Jr., "The Mechanical Properties of in-Situ Composites," JOM Journal of the Minerals, Metals and Materials Society, Vol. 49, No. 8, 1997, pp. 35-39. doi:10.1007/BF02914400 